\title{
Rhizosphere Streptomycetes Producing Antifungal to Candida albicans ATCC 10231 and $C$. albicans ATCC 24433 from Various Plants
}

\author{
Eti Sumiati ${ }^{1}$, Dewi Nur Anggraeni ${ }^{2}$ \\ ${ }^{1}$ Department of Health, Sekolah Tinggi Ilmu Kesehatan Mataram, Indonesia. 83116 \\ ${ }^{2}$ Faculty of Biology, Universitas Medan Area, Indonesia. 20223 \\ \{sumiatie070@gmail.com¹,dewinur@staff.uma.ac.id²\}
}

\begin{abstract}
A research on potency of rhizosphere streptomycetes producing antifungal on various plants (Cyperus rotundus L., Zea mays L., and Rhizopora mucronanata) was conducted. Twelve isolates of streptomycetes was tested to assess their potency in producing antifungal compound by using agar block method with Candida albicans ATCC 10231 and C. albicans ATCC 24433 as test fungi. The result showed that 3 isolates among 12 isolates showed their potency to produce antifungal. Based on their antifungal activity, 1 isolates (J10) were chosen to produce antifungal compound using fermentation method in GYE broth. Characterization of antifungal compound was carried out by using TLC, GC-MS and bioautographic test. The result of bioautography test showed that the spot from TLC of J10 isolates could inhibit C. albicans ATCC 10231 growth. Identification of antifungal compound of J10 by using TLC analysis and spray reagent suggested that then alkaloid, flavonoid, and phenol class of compound.
\end{abstract}

Keywords: Streptomycetes, Rhizosphere, Antibiotic antifungal.

\section{Introduction}

The emergence of the problem of infection caused by microbes, especially fungi in human life is a problem that does not end because it always raises new problems that are quite disturbing and detrimental to humans. These losses occur in various fields such as health (Akhand et al., 2010; Muiru et al., 2008)), agriculture, and plantations (Joo, 2005; Boruwa et al., 2004) so that handling these problems is very necessary. Strains to the Streptomyces genus are microbial groups whose members are the largest antibiotic producers because $75 \%$ of the antibiotics that have been found are from strains to the genus Streptomyces (Akhand et al, 2010). Iwamoto et al. (1990) succeeded in finding a new (anticandide) antifungal FR109615 derived from Streptomyces setonii No. 7562. Ohkuma et al. (1992) also found Sultriecin compounds produced by S. roseiscleroticus L827-7 (ATCC53903) which are new antifungal antibiotics as well as antitumor antibiotics. Furthermore Ueki et al. (1997) found UK-3A antifungal antibiotics produced by Steptomyces sp 517-02. Exploration and screening of secondary metabolites produced by strains Streptomyces are very important to obtain new compounds (antibiotics) that have the potential to inhibit harmful microbes (Hayakawa et al., 1996; Anupama et al., 2007; Singh et al., 2008). 
The study of de Araujol et al. (2000) succeeded found members of the genus Streptomyces endophytes in corn roots and leaves which acted as antibacterial and antifungal producers, Rahayu et al. (2007) succeeded in obtaining 5 isolates Streptomyces which had the potential to produce antibiotics from the rhizosphere of the scrub (Crotalaria striata), king grass (Zoysia matrella (L.) Merr) and jukut domdoman (Chrysopogen aciculatus (Retz) Trin). Based on this information, it is known that the opportunity to obtain bioactive compounds from streptomyces genus members associated with the rhizosphere region is still quite large so that it is necessary to explore strains Streptomyces from several rhizosphere to obtain antifungal compounds (Schlatter et al.,2009; Chatujinda et al., 2007; Balouiri et al., 2015 ). Thus, the purpose of this study was to determine the ability of streptomycetes isolates from various rhizosphere plants as antifungal producers and to determine the class of antifungal compounds produced by streptomycetes isolates.

\section{Material and Methods}

Twelve isolates of streptomycetes were namely R6, R7, R10, R18, NR1, NR4, NR20, NJ20, NJ25, J10, J16, and J20. Test fungi were Candida albicans ATCC 10231 and Candida albicans ATCC 24433. Medium for streptomycetes (SCA), for test fungi (YMEA), and fermentation medium (GYE). 2\% Tween 80 solution, aquades, and material for identification of active compounds.

Screening of Antifungal-Producing Streptomycetes Isolates; One-week-old streptomycetes isolates in oblique SCA medium suspended in $10 \mathrm{ml} 2 \%$ tween 80 . The suspension was taken as much as $0.1 \mathrm{ml}$ and inoculated on the SCA medium so that the spread plate was then incubated for two weeks. Subsequent culture results were used to test antifungal activity with a method so that blocks using cork borer were $12 \mathrm{~mm}$ in diameter. The test fungi that were incubated for two days were suspended in $10 \mathrm{ml}$ of sterile $2 \%$ Tween $80.0 .1 \mathrm{ml}$ of the test function was inoculated on a spread plate YMEA (yeast) medium. The inoculation results were perforated using cork borer with a diameter of $12 \mathrm{~mm}$. The part that has been perforated is filled with agar block containing streptomycetes isolates. The medium then incubated at room temperature (Nedialkova \& Naidenova, 2005) and observed the presence of inhibitory zones around the block.

Test for Selected Isolates; The best (selected) isolate fermented into liquid Glycerol Yeast Exstract (GYE) medium. Preparation of inoculum, isolates aged 2 weeks were suspended into tween $2 \%, 2 \mathrm{ml}$ of suspension was inoculated into $40 \mathrm{ml}$ liquid GYE medium. The medium was incubated in a sheker incubator at a temperature of $250 \mathrm{C}$ at a speed of $150 \mathrm{rpm}$ for two days. The inoculum that was made was taken as much as $5 \mathrm{ml}$ and inoculated into a $100 \mathrm{ml}$ liquid fermentation (GYE) medium, then incubated in a sheker incubator temperature of $250 \mathrm{C}$ at a speed of $150 \mathrm{rpm}$ for five days. The fermented product is then centrifuged at a speed of 5000 rpm for 20 minutes (Worang, 2003). The supernatant was taken and extracted with technical ethyl acetate using a separating funnel. The upper phase is taken and the lower phase is collected to be extracted again with ethyl acetate solvents up to three repetitions. The extraction results were evaporated at the waterbath temperature of 500C to dry (dry extract).

Characterization and Identification of Antifungal Compounds; Monitoring compounds by TLC (a) The extract was bottled on a silica gel F254 plate using a capillary tube, with a $1 \mathrm{~cm}$ bottling distance between each extract, the silica plate was dried. The silica plate that has been bottled with the extract is put into the developer tank which has been filled with the mobile phase namely chloroform: ethyl acetate with a ratio of 10: 1 . The chromatography results are air dried and seen under UV254 nm and UV366 nm and sprayed with spray reagents. 
Bioautography Test (b) The silica gel plate produced by TLC or which has been developed in the developer tank is drained until the eluent evaporates (dries). Then the silica gel plate was cut along the eluent development boundary and then tested on the test fungi by attaching the plate to the test medium which was inoculated with the test fungi and stored in the refrigerator for 20 minutes or until the compound could be distributed into the medium containing the test function. After 20 minutes, the medium is removed from the refrigerator and the plate that has been attached to the medium is removed from the medium. The medium was incubated for 24 hours at room temperature and it was seen that the barrier area around the site was attached to the TLC result plate (Isnaeni, 2005). Identification of Active Compounds (c) Identification of active compounds was carried out by spraying the results of TLC with various spray reagents and by the GC-MS method.

\section{Results and Discussion}

\section{Screening of Antifungal-Producing Streptomycetes Isolates}

Twelve streptomycetes isolates were tested for their ability to inhibit the test fungi (pathogenic fungi). The isolates were tested for antifungal activity against Candida albicans ATCC 10231 and C. albicans ATCC 24433. The results showed that as many as 3 streptomycetes isolates had the potential to produce antifungal compounds with different abilities in inhibiting the test function. These differences may be influenced by several factors, namely the composition of the medium and culture conditions such as $\mathrm{pH}$, temperature, carbon source, nitrogen source, and different incubation times for each strain. streptomycetes (Oskay, 2010). The screening of antifungal activity of each strain is very important given the presence of streptomycetes strains capable of producing more than one type of secondary metabolite such as S. griseus which produces antibacterial streptomycin and cycloheximide antifungal (Whiffen et al., 1946).

The screening results of antifungal-producing streptomycetes isolates are presented in Table 1. Of the three isolates, one isolate, $\mathrm{J} 10$, was considered to be the most effective in inhibiting the test fungus so that this isolate was selected for the production of antifungal compounds. Figure 1 is the result of antifungal activity of J10 isolates. Selected isolates, namely J10, were tested for the ability to produce antifungal compounds by fermentation using liquid GYE medium. Fermentation is carried out for five days resulting in a medium that is cloudy yellow (Image not shown).

Table 1. Results of screening for antifungal-producing streptomycetes isolates

\begin{tabular}{lclc}
\hline & & \multicolumn{2}{c}{ Test Fungi } \\
No & Test Isolates & C.a 1 & C.a 2 \\
\hline 1 & R6 & 0 & 2,3 \\
2 & R7 & 0 & 0 \\
3 & R10 & 0 & 0 \\
4 & R18 & 0 & 0 \\
5 & NR1 & 0 & 0 \\
6 & NR4 & 0 & 0 \\
7 & NR20 & 0 & 0 \\
8 & NJ20 & 0 & 0 \\
9 & NJ25 & 0 & 0 \\
10 & J10 & 5,2 & 5,5 \\
11 & J16 & 2,8 & 3,22 \\
12 & J20 & 0 & 0 \\
\hline
\end{tabular}




\begin{tabular}{llll}
\hline 13 & $41 X$ & 0 & 0 \\
14 & 20 & 0 & 0 \\
15 & 11 & 0 & 0 \\
16 & 26 & 0 & 0 \\
17 & L10 & 0 & 0 \\
\hline
\end{tabular}

Note: Candida albicans ATCC 10231 (C.a 1) dan Candida albicans ATCC 24433 (C.a 2)

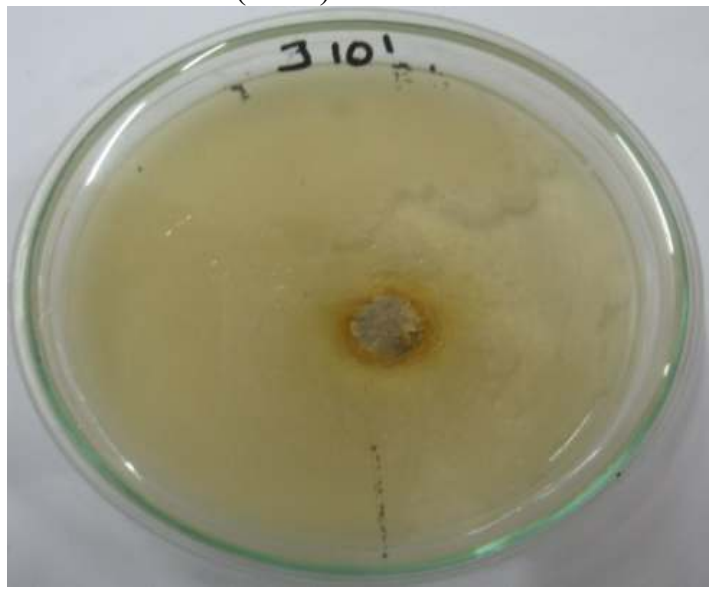

Figure 1. Anticandide activity of J10 isolates against Candida albicans ATCC 10231

\section{Characterization and Identification of Antifungal Compounds}

Three stages were carried out to characterize and identify antifungal compounds namely TLC monitoring compounds, bioautography tests, and identification with spray reagents and identification approaches using the GC-MS method. The results of monitoring compounds by TLC are presented in Figure 2, these results indicate that there are several spots detected. Detection of TLC on UV254 nm produces blue while UV366 nm produces purple fluorescence. The results of spraying with $\mathrm{AlCl} 3$ give a yellow color that refers to flavonoid compounds, with purple anisaldehyde which refers to phenol compounds, and with dragendorff it produces a yellowish orange color indicating alkaloid compounds, with positive purple anisaldehyde for phenol, and positive brown cerium sulfate for general organic compounds that are matched based on Krebs et al. (1969) and Sutrisno (1986). 


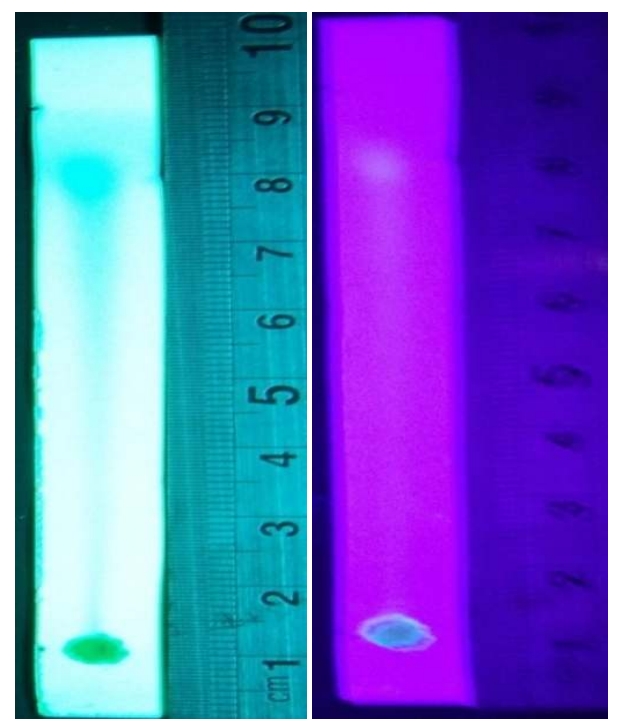

Figure 2. Results of TLC of ethyl acetate extract isolates J10 which detected UV254 (blue) and UV366 (purple)

The results of identification of compounds with several spray reactions showed that the ethyl acetate extract of J10 isolates contained flavonoid compounds, phenols and alkaloids based on the color produced after spraying with several spray reagents. Most of these compounds have been known to have antifungal activity. According to Cowan (1999) flavonoid compounds have activity to damage cell membranes and cell walls of fungi and can provide it with a fungi protein complex. While alkaloid compounds have the ability to bind to the DNA of fungi. It is possible that the activity of these two compounds causes inhibition and even death in fungal cells. The results of identification of compound groups using spray reagents are presented in Table 2.

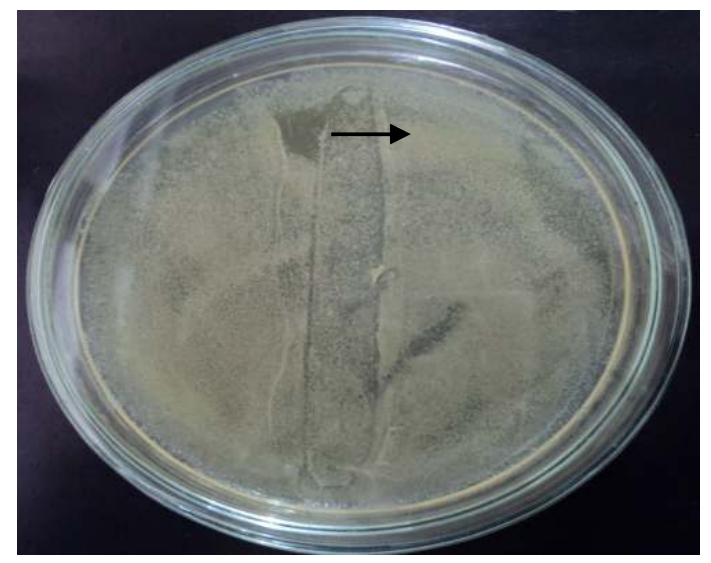

Figure 3. Results of bioautography test of J10 isolates against Candida albicans ATCC 10231 
The bioautography test of ethyl acetate extract isolate J10 (TLC results) on C. albicans ATCC 10231 and ethyl acetate extract of J10 isolate are presented in Figure 3. The results showed that spot yield of TLC extract of ethyl acetate J10 isolate could inhibit C. albicans ATCC 10231.

Table 2. Results of identification of compound groups using TLC analysis and spray reagents.

\begin{tabular}{|c|c|c|c|c|c|}
\hline No & $\begin{array}{l}\text { Class of } \\
\text { Compound }\end{array}$ & $\begin{array}{l}\text { Spray } \\
\text { Reagent }\end{array}$ & $\begin{array}{l}\text { Standard } \\
\text { Color }\end{array}$ & $\begin{array}{l}\text { Result of } \\
\text { Test }\end{array}$ & $\begin{array}{l}\mathrm{Rf} \\
\mathrm{J} 10\end{array}$ \\
\hline 1 & Flavonoids & $\mathrm{AlCl}_{3}$ & Yellow & + & \\
\hline 2 & Sugar & Anisaldehyde & 0,04 & & \\
\hline 3 & Steroids & Anisaldehyde & Red & - & - \\
\hline 4 & Terpen & Anisaldehyde & Green & - & - \\
\hline 5 & Phenol & Anisaldehyde & Blue & - & - \\
\hline 6 & Alkaloids & Dragendorff & Purple & + & \\
\hline 7 & Amine & Ninhydrin & $0,37 \& 0,9$ & & \\
\hline 8 & Phenol & $\mathrm{FeCl}_{3}$ & Yellow-orange & + & 0,3 \\
\hline 9 & Hydroxamic & $\mathrm{FeCl}_{3}$ & Blue & - & - \\
\hline \multirow[t]{3}{*}{10} & acid & Serium (IV) & Blue & - & - \\
\hline & General Organic & Sulfat & Red & - & - \\
\hline & compound & & Choco & + & 0,5 \\
\hline
\end{tabular}

Note: (+) Indicates the identification of a class of compounds

(-) Group of compounds not identified.

The results of identification of antifungal compounds by GC-MS showed that the ethyl acetate extract of J10 isolate was not detected by GC-MS. This is probably due to improper column selection and temperature regulation so that the compounds in the ethyl acetate extract J10 cannot be detected by GC-MS devices (GC-MS results are not shown). The GC-MS tool used in this study had a temperature of $300^{\circ} \mathrm{C}$.

\section{Conclusion}

Streptomycetes isolates from various plant rhizosphere have the potential to produce antifungal compounds. The group of antifungal compounds produced by streptomycetes is a class of alkaloid compounds, phenols and flavonoids.

\section{References}

[1] Akhand, M. A. M., Bari, M. A. A., Islam, M. A., and Khondkar1, P. 2010. Characterization and Antimicrobial Activities of a Metabolite from a New Streptomyces Species from Bangladeshi Soil. Journal of Scientific Research 2 (1): 178-185.

[2] Anupama, M. Narayana, K. J. P., and Vijayalakshmi, M. 2007. Screening of Streptomyces purpeofuscus for Antimicrobial Metabolites. Research Journal of Microbiology. 2 (12): 992-994.

[3] Balouiri, M., Bouhdid, S., Harki, H., E., Sadiki, M., Edrhiri, W.,O., \& Ibnsouda, K., S., 2015. Antifungal activity Of Bacillus Spp. Isolates From Calotropis Procera 
Ait Rhizosphere against Candida albicans. Asian Journal of Pharmaceutical and Clinical Research. 8 (2)

[4] Boruwa, J., Kalita, B., Barua, N. C., Borah, J. C., Mazumder, S., Thakur, D., Gogoi, D.K. \& Bora, T. C., 2004. Synthesis, absolute stereochemistry and molecular design of the new antifungal and antibacterial antibiotic produced by Streptomyces sp.201. Bioorganic \& Medicinal Chemistry Letters. 14 : 3571-3574.

[5] Chatujinda, S., Tanasupawat, S., Amnuoypol, S., Chaichantipyuth, C., 2007. Identification And Antimicrobial Activities of Streptomyces Strain Isolated From Soils. J Health Res 21 (3): 195-200

[6] Cowan, M. M., 1999, Plant Products as Antimicrobial Agents, American Sosiety for Microbiology, Reviews. 12 (4); 564-582.

[7] de Araujol, J. M., Silva, A. C. da., \& Azevedo, J. L. 2000. Isolation of Endophytic Actinomycetes from Roots and leaves of Maize (Zea mays. L.) Brazilian Archives of Biology and Technology., 43 (4) : 52-58.

[8] Hayakawa, M. Momose, Y, Yamazaki, T \& Nonomura, H. 1996. A Method for the selective Isolation of Microtetraspora Glauca and Related Fourspored Actinomycetes from Soil. Journal of Applied Bacteriol. 80: 375-386.

[9] Isnaeni. 2005. Bioautografi Antibiotik Hasil Fermentasi Mutan Streptomyces griseus ATCC 10137. Majalah Farmasi Airlangga, 5 (1) : 16-19.

[10] Iwamoto, T., Tsujii, E., Ezaki, M., Fujie, A., Hashimoto, S., Okuhara, M., Kohsaka, M., \& Imanaka, H. 1990. FR109615, A New Antifungal Antibiotic from Streptomyces setonii. Journal of Antibiotics, 43 (1) : 1-7.

[11] Joo, G. J. 2005. Production of An Antifungal Substance for Biological Control of Phytophthora capsici Causing Phytophthora Blight in Red-peppers by Streptomyces halstedii. Biotechnology Letter. 27 : 201-205.

[12] Krebs, K.G., D. Heusser \& H. Wimmer. Spray Reagents. In Thin-Layer Chromatography : A Laboratory Handbook $2^{\text {nd }}$ Edition (E. Stahl Ed.). SpringerVerlag : Berlin.

[13] Muiru, W. M., Mutitu, E. W., \& Mukunya, D. M. 2008. Identification of Selected Actinomycete Isolates and Characterization of Their Antibiotic Metabolites. Journal of Biological Sciences. 8 (6): 1021-1026.

[14] Nedialkova, D. \& M. Naidenova. 2005. Screening The Antimicrobial Activity of Actinomycetes Strains Isolaled from Antartica. Journal of Culture Collection 4 : $29-35$.

[15] Ohkuma, H., Naruse, N., Nishiyama, Y., Tsuno, T., Hoshino, Y., Sawada, Y., Konishi, M., and Oki, T., 1992. Sultriecin a new Antifungal and Antitumor Antibiotic from Streptomyces roseiscleroticus Production, Isolation, Structure and Biological Activity. The Journal of Antibiotics. 45 (8): 1239-1249.

[16] Oskay, M. 2009. Antifungal and Antibacterial Compounds from Streptomyces Strains. African Journal of Biotechnology. 8 (13) : 3007-3017.

[17] Rahayu, T., Maryati, Sembiring, L., \& Soegihardjo, C. J. 2007. Isolation and Characterization of Streptomyces potential as an Antimicrobial from Rizosphere. Collection of Summary of Research Results Workshop on Presentation of Research by DP2M Dikti in 2007. UMS, Surakarta.

[18] Singh, V., Tripathi, C.,K.,M., \& Bihari, V., 2008. Production, Optimization and Purification of An Antifunfal Compound From Streptomyces capoamus MTCC 8123. Med.Chem Res. 17: 94-102 
[19] Sutrisno, R.B. 1986. TLC (Thin Layer Chromatography). Department of Farmasi, Universitas Pancasila : Jakarta

[20] Schlatter, D., Fubuh, A., Xiao, K., Hernandez, D., Hobbie, S., \& Kinkel, L., 2009. Resource Amendments Influence Density and Competitive Phenotypes of Streptomyces in soil. Microb Ecol. 57: 413-420. DOI 10.1007/s00248-008-9433-4

[21] Ueki, M., Kusumoto, A., Hanafi, M., Shibata, K., Tanaka, T., \& Taniguchi, M., 1997. UK-3A, a Novel Antifungal Antibiotic from Streptomyces sp. 517-02: Fermentation, Isolation, Structural Elucidation and Biological Properties. The Journal of Antibiotics 50 (7): 551-555.

[22] Worang, R.L. 2003. Endophytic fungi as Antibiotic Producing. Tesis. Department of Biology, Universitas Gadjah Mada : Yogyakarta. 